\title{
Amikacin pharmacokinetic/ pharmacodynamic in intensive care unit: a prospective database
}

\author{
Elsa Logre ${ }^{1 *} \mathbb{C}$, Maya Enser ${ }^{1}$, Sébastien Tanaka ${ }^{2,3}$, Marie Dubert ${ }^{4}$, Aurore Claudinon ${ }^{5}$, Nathalie Grall ${ }^{6}$, \\ Hervé Mentec ${ }^{1}$, Philippe Montravers ${ }^{2}$ and Olivier Pajot ${ }^{1}$
}

\begin{abstract}
Background: Aminoglycosides have a concentration-dependent therapeutic effect when peak serum concentration $\left(C_{\max }\right)$ reaches eight to tenfold the minimal inhibitory concentration (MIC). With an amikacin MIC of $8 \mathrm{mg} / \mathrm{L}$, the $C_{\max }$ should be $64-80 \mathrm{mg} / \mathrm{L}$. This objective is based on clinical breakpoints and not on measured MIC. This study aimed to assess the proportion of patients achieving the pharmacokinetic/pharmacodynamic (PK/PD) target $C_{\max } / \mathrm{MIC} \geq 8$ using the measured MIC in critically ill patients treated for documented Gram-negative bacilli (GNB) infections.

Methods: Retrospective analysis from February 2016 to December 2017 of a prospective database conducted in 2 intensive care units (ICU). All patients with documented severe GNB infections treated with amikacin (single daily dose of $25 \mathrm{mg} / \mathrm{kg}$ of total body weight (TBW)) with both MIC and $C_{\max }$ measurements at first day of treatment (D1) were included. Results are expressed in $\mathrm{n}(\%)$ or median [min-max].

Results: 93 patients with 98 GNB-documented infections were included. The median $C_{\max }$ was $55.2 \mathrm{mg} / \mathrm{L}$ [12.2165.7] and the median MIC was $2 \mathrm{mg} / \mathrm{L}$ [0.19-16]. $C_{\max } / \mathrm{MIC}$ ratio $\geq 8$ was achieved in 87 patients (88.8\%) while a $C_{\max } \geq 64 \mathrm{mg} / \mathrm{L}$ was achieved in only 38 patients (38.7\%). Overall probability of PK/PD target attainment was $93 \%$. No correlation was found between $C_{\max } / \mathrm{MIC}$ ratio and clinical outcome at D8 and D28.

Conclusion: According to PK/PD parameters observed in our study, single daily dose of amikacin $25 \mathrm{mg} / \mathrm{kg}$ of TBW appears to be sufficient in most critically ill patients treated for severe GNB infections.
\end{abstract}

Keywords: Pharmacokinetic, Pharmacodynamic, Amikacin, Intensive care unit

\section{Key points}

- A single daily dose of amikacin (25 mg/kg of TBW) appears to be sufficient in most critically ill patients treated for severe GNB infections.

- An exclusive focus on $C_{\max }$ without MIC measurement is probably not suitable for a reliable pharmacodynamic assessment of amikacin therapy.

\footnotetext{
*Correspondence: elsa.logre@gmail.com

${ }^{1} \mathrm{CH}$ Argenteuil, réanimation polyvalente, 69 rue du Lieutenant-Colonel Prudhon, Argenteuil, France

Full list of author information is available at the end of the article
}

\section{Background}

Management of severe infections in intensive care unit (ICU) represent a major challenge for clinicians, and prompt initiation of effective antibiotic therapy is essential to improve patient's survival $[1,2]$. In patients with septic shock, guidelines recommend combination antimicrobial therapy with aminoglycosides, particularly when Gram-negative bacilli (GNBs) are suspected or documented [2].

Optimal anti-GNB activity of amikacin is achieved when peak serum concentration $\left(C_{\max }\right)$ reach eight to tenfold the minimal inhibitory concentration (MIC) [3]. With an amikacin MIC as high as $8 \mathrm{mg} / \mathrm{L}$ (beyond 
which the bacteria have intermediate susceptibility based on clinical breakpoints defined by EUCAST), the target $C_{\max }$ should therefore be $64-80 \mathrm{mg} / \mathrm{L}$ as recommended by French guidelines on aminoglycosides use $[4,5]$.

Previously published data with single daily dose of 15 to $25 \mathrm{mg} / \mathrm{kg}$ of amikacin pointed out that this target of $C_{\max } \geq 64 \mathrm{mg} / \mathrm{L}$ was not reached for most patients [6-8]. Thus, in order to optimize the $C_{\max /} \mathrm{MIC}$ ratio, it is suggested to increase amikacin loading dose up to $30 \mathrm{mg} / \mathrm{kg} /$ day of total body weight (TBW) for severe patients [5].

However, in most clinical studies and in daily practice, the pharmacological efficacy of amikacin is only assessed by $C_{\max }$ measurements (objective of $C_{\max } \geq 64 \mathrm{mg} / \mathrm{L}$ based on clinical breakpoints) and not by measured MICs.

To our knowledge, few studies have reported the antibacterial effect of amikacin based on $C_{\max } / \mathrm{MIC}$ ratio using measured MIC for each patient profile.

We therefore undertook a retrospective analysis of our prospective database to assess pharmacodynamic target attainment $\left(C_{\max } / \mathrm{MIC} \geq 8\right)$ - considering amikacin measured MICs-in critically ill patients empirically treated for documented severe GNB infections.

\section{Methods}

\section{Study design, settings and patients}

We performed a retrospective analysis from February 2016 to December 2017 of a prospective observational database conducted in 2 ICUs.

The ANSM (French National Agency for Medicines and Health Products Safety) registration number of the study is 2017-A01083-50. French Data Protection Agency declaration of the database was done. The local hospital ethics Committee was consulted and did not indicate the need for a formal approval, according to French law [9].

ICU patients who met the following criteria were included: (i) empirical combination treatment including amikacin for sepsis or septic shock (as defined by the 3rd Surviving Sepsis Campaign) [2], with a diagnosis made according to CDC infections classifications [10]; (ii) amikacin administered according to the standardized protocol of both ICUs (described below) and following microbiological sample for pathogen identification and (iv) documented GNB infection with amikacin MIC measurement available.

Patients with the following criteria were excluded: (i) death within $48 \mathrm{~h}$ after amikacin administration; (ii) no GNB documented in microbiological sample; (iii) incorrect amikacin regimen; (iv) resistance to amikacin on antibiogram; (v) no MIC measurement available.

\section{Protocol}

Patients were receiving empiric antibiotic therapy with amikacin in combination with one (or more) other antimicrobial agents, whose choice was left to the discretion of clinicians.

Amikacin was administered according to the standardized protocol of both ICUs (in place since 2015): recommended single daily dose of $25 \mathrm{mg} / \mathrm{kg}$ of TBW (weight of the day, using a weighing bed), diluted in $50 \mathrm{~mL} \mathrm{NaCl} 0.9 \%$ and continuously infused (electric syringe) over $30 \mathrm{~min}$.

The duration of treatment with amikacin was left to the discretion of clinicians.

According to the standardized protocol, peak amikacin concentration was measured $30 \mathrm{~min}$ after the end of infusion $\left(C_{\max }\right)$ and trough serum concentration $24 \mathrm{~h}$ after the end of infusion and before the next injection of amikacin, if necessary $\left(C_{\mathrm{min}}\right)$.

Reinjection was not recommended if $C_{\min }$ was beyond $2.5 \mathrm{mg} / \mathrm{L}$, according to national guidelines [5].

When GNB was identified, clinicians could ask the microbiology laboratory of each hospital to perform amikacin MIC measurement for patients who received amikacin. Measurement was performed using a diffusion technique in an agar medium (Etest strips) for each strain according to the manufacturer's instructions (bioMérieux laboratory, Marcy l'étoile, France). The toxicology laboratory performed amikacin serum concentrations measurements as a routine procedure available $24 \mathrm{~h}$ a day, 7 days a week, using a fluorescence polarization immunoassay (FPIA) [11].

\section{Objectives of the study and endpoints}

The main objective of the study was to determine the proportion of patients achieving a $C_{\max } / \mathrm{MIC}$ ratio $\geq 8$, using both MIC and $C_{\max }$ measurements at first day of treatment.

In case of a polymicrobial infection, the highest amikacin MIC among identified GNBs was considered.

The secondary objectives were to describe amikacin pharmacological parameters; to determine the overall probability of pharmacodynamic target attainment in patients treated with a $25 \mathrm{mg} / \mathrm{kg}$ daily dose of amikacin, taking into account the distribution of $C_{\max }$ and MIC; to identify covariables of amikacin $C_{\max }$ in critically ill patients. We also evaluated the impact of amikacin pharmacokinetic/pharmacodynamic (PK/PD) parameters on clinical outcome. Poor clinical outcome was defined as a composite criteria: SOFA score $>3$ or death at D8. 


\section{Data collection}

D1 was defined as the first day of amikacin administration (calendar day).

For all patients enrolled, demographic data, Simplified Acute Physiology score (SAPS 2) [12], SOFA score (Sequential Organ Failure Assessment) [13], reason for ICU admission, type of infection, and clinical and biological parameters were retrospectively collected on D1 and D8.

Daily fluid intake on D1, vasopressor support, duration of mechanical ventilation, use of renal replacement therapy (RRT), of Optiflow ${ }^{\circledR}$ or ECMO (extracorporeal membrane oxygenation) were noted, if applicable.

Patient vital status was assessed on D8 and D28.

\section{Statistical analysis}

Variables were expressed as numbers (percentages) and medians [minimal-maximal].

Patients or infections were compared according to different pharmacokinetic and pharmacodynamic parameters $\left(C_{\max }, C_{\max } / \mathrm{MIC}\right.$ ratio $)$ on $\mathrm{D} 1$, and for the clinical outcome evaluated on D8 and D28. A non-parametric test was used to compare the continuous variables (Mann-Whitney test), and an appropriate test was used to compare the categorical variables (Chi-square test or Fisher's exact test).

Variables associated with $C_{\max } \geq 64 \mathrm{mg} / \mathrm{L}$ in univariate analysis were included in a multivariate analysis using stepwise logistic regression.

A p value less than 0.05 was considered statistically significant.

The overall probability of pharmacodynamic target $\mathrm{C}_{\max } / \mathrm{MIC}$ ratio $\geq 8$ was calculated by adding the individual probabilities for each observed MIC value, taking into account the frequency of observation of each MIC and the observed $C_{\max }$ distribution.

The statistical analyses were performed using $\mathrm{R}$ software (Team RC) and JMP 14.1 (SAS Institute Inc, Cary, NC, USA http://www.R-projectorg/).

\section{Results}

\section{Patients characteristics}

From February 2016 to December 2017, 93 patients with 98 GNB infections were eligible (Fig. 1). Patients characteristics at admission are reported in Table 1.

The clinical characteristics of patients and infections on D1 are reported in Table 1.

A $\beta$-lactam (4th generation cephalosporin or piperacillin-tazobactam in $49 \%$ and carbapenem in $32.6 \%$ of infections) was used in combination with amikacin in 97 infections (99\%). Empiric antibiotic therapy was active against the pathogen(s) in 87 infections (89\%) among which amikacin was the only active antibiotic in only 5 (5.1\%) infections.

Amikacin median MIC for all GNBs identified in our study was $2 \mathrm{mg} / \mathrm{L}$ [0.19-16] and the median MIC of Pseudomonas aeruginosa was $3 \mathrm{mg} / \mathrm{L} \mathrm{[1-8].} \mathrm{Two} \mathrm{infec-}$ tions involved bacteria with amikacin MIC of $12 \mathrm{mg} / \mathrm{L}$ and $16 \mathrm{mg} / \mathrm{L}$, respectively (intermediate susceptibility according to EUCAST).

MICs distribution of amikacin is available in (Additional file 1: Fig. S1).

\section{Primary outcome}

The $C_{\max } / \mathrm{MIC}$ ratio, calculated for each infectious episodes on D1, was above or equal to 8 in 87 infectious episodes (88.8\%) (Table 2). Excluding the two infections involving GNB with intermediate susceptibility according to EUCAST, which usually discourage amikacin prescription, a $C_{\max } / C M I$ ratio $\geq 8$ was achieved in $91 \%$ of treated infections.

\section{Secondary outcomes \\ Pharmacological parameters}

The PK/PD parameters of amikacin are reported in Table 2. The median $C_{\max }$ on D1 was $55.2 \mathrm{mg} / \mathrm{L}$ [12.2165.7]. In $38.8 \%$ of infectious episodes, amikacin $C_{\max }$ was $\geq 64 \mathrm{mg} / \mathrm{L}$ on D1.

Pharmacodynamic description was also performed including the following criteria: $C_{\max } \geq 80 \mathrm{mg} / \mathrm{L}$ and $C_{\max } /$ MIC ratio $\geq 10$ (Table 2).

The overall probability of target attainment $C_{\max } /$ MIC $\geq 8$, with single daily dose of $25 \mathrm{mg} / \mathrm{kg}$ amikacin under the study conditions, according to $C_{\max }$ and MICs distributions, was $93 \%$ (Fig. 2). This probability was $89 \%$ for a target of $C_{\max } / \mathrm{MIC} \geq 10$.

GNBs infections treated with a $C_{\max } / \mathrm{CMI}$ ratio $<8$ versus $\geq 8$ were associated with both higher amikacin MICs (8 [4-16] versus $2 \mathrm{mg} / \mathrm{L}[0.19-8], p<0.0001)$ and lower $C_{\max }$ on D1 (34.2 [12.2-77.8] versus $57.6 \mathrm{mg} / \mathrm{L}$ [22.3165.7], $p=0.001$ ) (Additional file 1: Table S1).

\section{$C_{\max }$ covariables}

Factors associated with a $C_{\max } \geq 64 \mathrm{mg} / \mathrm{L}$ in univariate analysis are reported in Table 3. In multivariate analysis, after adjustment with the SOFA score on D1 and the administered dose, serum creatinine on D1 was the only factor independently associated with a $C_{\max } \geq 64 \mathrm{mg} / \mathrm{L}$ $(\mathrm{OR}=1.01[1.00-1.01], p=0.004)$.

\section{Clinical outcome}

The median length of stay in intensive care unit was 16 days [2-123]. Overall mortality at D28 was $24.7 \%$ and ICU mortality was $22.6 \%$. 


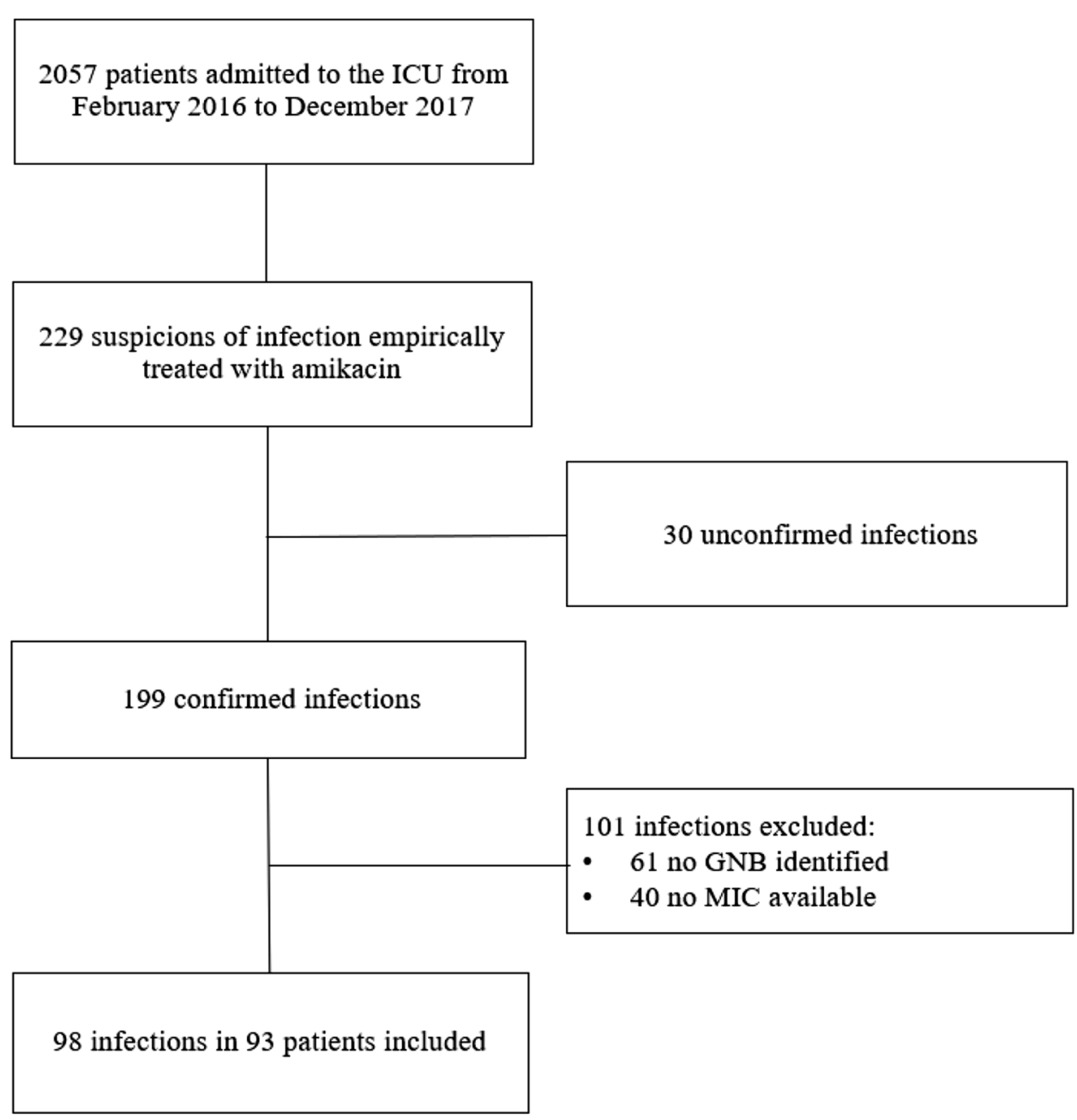

Fig. 1 Flowchart of the study

There was no significant differences in mortality and SOFA score on D8 according to the $C_{\max } / \mathrm{MIC}$ ratio. Similarly, the clinical outcome of patients on D28 was not different (Table 4).

PK/PD parameters were not different whether the clinical outcome was favorable or poor on D8 (Additional file 1: Table S2), and similarly between patients alive or dead on D28 (Additional file 1: Table S3).

\section{Discussion}

In this prospective database performed in critically ill patients with documented GNB infections and receiving a $25 \mathrm{mg} / \mathrm{kg}$ single daily dose of amikacin, the overall probability of target attainment $C_{\max } / \mathrm{MIC}$ ratio $\geq 8$ was 93\% according to our $C_{\max }$ and MIC distributions.

These data are not in accordance with previous studies that showed a risk of treatment failure, only based on amikacin $C_{\max }$ measurement (64 to $80 \mathrm{mg} / \mathrm{L}$ ) or $C_{\max } /$
MIC ratio calculated with clinical breakpoints (8 to 10-fold a $8 \mathrm{mg} / \mathrm{L} \mathrm{MIC)} \mathrm{[7,} \mathrm{8].} \mathrm{Most} \mathrm{studies} \mathrm{concluded}$ that a $25 \mathrm{mg} / \mathrm{kg}$ loading dose of amikacin is insufficient in critically ill patients to achieve these pharmacodynamic targets and therefore endanger treatment efficacy.

However, in our study, although only $38.8 \%$ patients only achieved an amikacin $C_{\max } \geq 64 \mathrm{mg} / \mathrm{L}$, more than $90 \%$ had a $C_{\max } /$ MIC ratio over the pharmacodynamic target $(\geq 8)$ when susceptible strains were involved.

Amikacin $C_{\max }$ measurements ranged from 12.2 to $165.7 \mathrm{mg} / \mathrm{L}$ with a median of $55.2 \mathrm{mg} / \mathrm{L}$. This significant dispersion found in several studies conducted in ICUs is explained by the inter-individual variability of pharmacokinetic parameters in these patients $[7,8,14-16]$.

Nevertheless, in our study, the median amikacin $C_{\max }$ was much lower than in the literature (summarized in Additional file 1: Table S4). Indeed, three studies performed in critically ill patients and receiving a $25 \mathrm{mg} / \mathrm{kg}$ 
Table 1 Patients and infections characteristics on admission and on D1

\begin{tabular}{|c|c|}
\hline Patients characteristics on admission & Values $(n=93)$ \\
\hline Age (years) & 62 [24-90] \\
\hline Female & $37(40)$ \\
\hline BMI $\left(\mathrm{kg} / \mathrm{m}^{2}\right)$ & 25 [15-45] \\
\hline Chronic renal failure & $17(18.2)$ \\
\hline SAPS 2 admission & $54[15-124]$ \\
\hline \multicolumn{2}{|l|}{ Types of admission } \\
\hline Medical & $52(56)$ \\
\hline Scheduled surgery & $13(14)$ \\
\hline Urgent surgery & $28(30)$ \\
\hline \multicolumn{2}{|l|}{ Reasons for admission } \\
\hline Septic shock & $36(39)$ \\
\hline Acute respiratory failure & $30(30.6)$ \\
\hline Heart failure & $8(8.1)$ \\
\hline Pulmonary transplantation & $8(8.1)$ \\
\hline Other & $16(16.2)$ \\
\hline Clinical characteristics on D1 & Values $(n=98)$ \\
\hline Delay admission-D1 (day) & $4.5[1-71]$ \\
\hline Weight (kg) & $77[45-130]$ \\
\hline Temperature $\left({ }^{\circ} \mathrm{C}\right)$ & $37.8[35-41]$ \\
\hline Leukocytes (G/L) & $14.3[0.1-78.7]$ \\
\hline Creatinine $(\mu \mathrm{mol} / \mathrm{L})$ & 77 [23-609] \\
\hline SOFA score & $7[0-17]$ \\
\hline Vasopressors & $58(59.1)$ \\
\hline Mechanical ventilation & $62(63.3)$ \\
\hline \multicolumn{2}{|l|}{ Infections characteristics } \\
\hline \multicolumn{2}{|l|}{ Types of infection } \\
\hline Pulmonary & $52(53)$ \\
\hline Intra-abdominal & $24(24.5)$ \\
\hline Urinary & $15(15.3)$ \\
\hline Cutaneous & $3(3.1)$ \\
\hline Other & $4(4)$ \\
\hline Bacteriemia & $14(14.3)$ \\
\hline Polymicrobial infections & $46(46.7)$ \\
\hline \multicolumn{2}{|c|}{ Gram-negative bacilli documented $(n=132)$} \\
\hline E. coli & $41(31.1)$ \\
\hline P. aeruginosa & $39(29.5)$ \\
\hline E. cloacae & $10(7.6)$ \\
\hline K.pneumoniae & $11(8.3)$ \\
\hline Morganella spp & $8(6.1)$ \\
\hline P. mirabilis & $5(3.8)$ \\
\hline C. koseri & $5(3.8)$ \\
\hline Others & $13(9.8)$ \\
\hline Bacteria other than GNB identified & $35(35.7)$ \\
\hline
\end{tabular}

Data presented in $n(\%)$ or median [min-max]

(TBW) loading dose reported a median amikacin $C_{\max }$ around $70 \mathrm{mg} / \mathrm{L}[7,8,14]$ : De Montmollin et al. showed that $58 \%$ of patients enrolled reached an amikacin
Table 2 Pharmacokinetic/pharmacodynamic parameters observed

PK/PD parameters of amikacin

Total administered dose (mg)

1900 [1000-3250]

Dose administered by body weight on D1 (mg/kg) 25 [15.6-31.8]

Time [end of infusion $-C_{\max }$ measurement] (min) 30 [10-55]

$C_{\max } \mathrm{D} 1(\mathrm{mg} / \mathrm{L})$

$55.2[12.2-165.7]$

$C_{\max } \mathrm{D} 1 \geq 64 \mathrm{mg} / \mathrm{L}$

$38(38.8)$

$C_{\max } \mathrm{D} 1 \geq 80 \mathrm{mg} / \mathrm{L}$

$18(18.4)$

$C_{\max } / \mathrm{MIC}$ on $\mathrm{D} 1$

$23.1[1-169]$

$C_{\max } / \mathrm{MIC} \geq 8$ on D1 $87(88.8)$

$C_{\text {max }} / \mathrm{MIC} \geq 10$ on D1 $\quad 86(87.8)$

$C_{\min } \mathrm{D} 2 \geq 2.5 \mathrm{mg} / \mathrm{L}^{\mathrm{a}} \quad 49(59.8)$

Data presented in $n(\%)$ or median [min-max]

${ }^{a}$ Among the $82(84 \%) C_{\min }$ available on D2

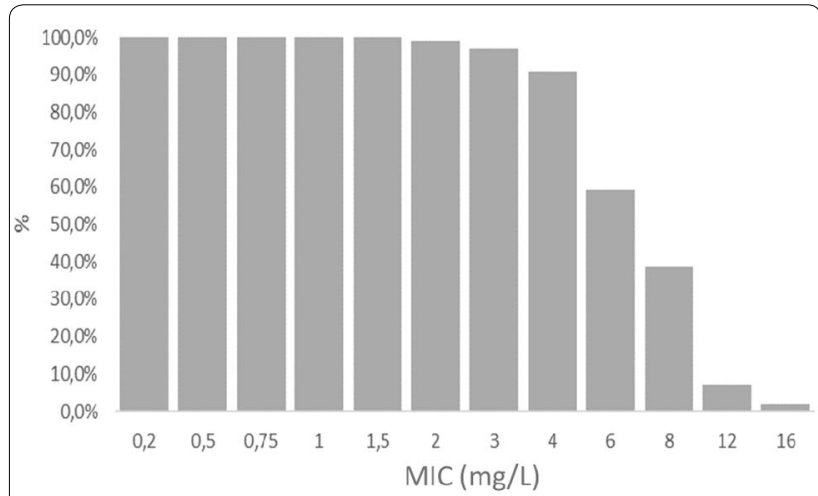

Fig. 2 Probability of achieving target $C_{\max } / \mathrm{MIC}$ ratio $\geq 8$ according to the MIC

$C_{\max } \geq 64 \mathrm{mg} / \mathrm{L}$ [7] and Taccone et al. reported $70 \%$ of patients achieving this target [8].

Patients characteristics in our study and those reported above seem similar especially in terms of severity (estimated by the SOFA score), but there are significant differences in renal function (renal replacement therapy resort and serum creatinine were lower in our patients). These differences are all the more important as serum creatinine is a covariable of the pharmacokinetic of aminosides, which seems decisive for $C_{\max }$. Indeed, to our knowledge, two studies identified renal function as a major co-variable of amikacin $C_{\max }$ in ICU patients and this may explain the lower amikacin $C_{\max }$ found in our study $[14,17]$. We confirm these results because, in multivariate analysis, after adjustment with the SOFA score on D1 and the administered dose, serum creatinine on D1 was the only factor independently associated with a $C_{\max } \geq 64 \mathrm{mg} / \mathrm{L}(\mathrm{OR}=1.01$ [1.00-1.01], $\mathrm{p}=0.004)$. 
Table 3 Comparison of patients and treated infections, according to the 1 st $C_{\max }$ observed (on D1)

\begin{tabular}{|c|c|c|c|}
\hline \multirow[t]{3}{*}{ Patients data ${ }^{a}$} & \multicolumn{2}{|l|}{$C_{\max }$ on $\mathrm{D} 1$} & \multirow[t]{3}{*}{$p$} \\
\hline & $<64 \mathrm{mg} / \mathrm{L}$ & $\geq 64 \mathrm{mg} / \mathrm{L}$ & \\
\hline & $(n=56)$ & $(n=37)$ & \\
\hline Female & $20(35.7)$ & $17(45.9)$ & 0.32 \\
\hline Age (years) & 60 [24-90] & $66[46-88]$ & 0.038 \\
\hline BMl admission & $24.5[15-42.4]$ & $25.4[18.8-45.1]$ & 0.17 \\
\hline SAPS 2 admission & $51.5[15-105]$ & $54[29-124]$ & 0.38 \\
\hline Chronic renal failure & $7(12.5)$ & $10(27)$ & 0.10 \\
\hline Data on D1 & $(n=60)$ & $(n=38)$ & \\
\hline Admission time-D1 (d) & $5[1-71]$ & $4[1-35]$ & 0.25 \\
\hline Weight (kg) & $75.5[45-130]$ & $79.5[48-120]$ & 0.15 \\
\hline Weight gain/admission (kg) & $0[-15-25]$ & $0[-12-23]$ & 0.26 \\
\hline SOFA & $6.5[0-17]$ & $8[0-15]$ & 0.17 \\
\hline Mechanical ventilation & $41(68.3)$ & $21(55.2)$ & 0.19 \\
\hline Vasopressor support & $32(53.3)$ & $26(68.4)$ & 0.14 \\
\hline Renal replacement therapy & $2(3.3)$ & $3(7.9)$ & 0.37 \\
\hline Urine $24 \mathrm{~h}$ volume $(\mathrm{mL})$ & 1100 [0-5300] & $1225[0-4900]$ & 0.52 \\
\hline Serum creatinine $(\mu \mathrm{mol} / \mathrm{L})$ & $58.5[23-453]$ & $132[31-609]$ & 0.0003 \\
\hline 24-h fluid intake $(\mathrm{mL})$ & $3200[1000-12,642]$ & $2868[1000-11,000]$ & 0.90 \\
\hline Dose administered per kg (mg) & $25[15.6-31.8]$ & $25[20.3-31.3]$ & 0.11 \\
\hline Total dose administered (mg) & 1800 [1000-3250] & 2000 [1250-3000] & 0.034 \\
\hline
\end{tabular}

Data expressed in $\mathrm{n}(\%)$ or median [min-max]

a Comparison according to the $C_{\max }$ measured during the first episode of infection treated with amikacin

\begin{tabular}{|c|c|c|c|c|}
\hline \multirow[t]{2}{*}{ Overall population } & & \multicolumn{2}{|c|}{$C_{\max } / \mathrm{MIC}$ on $\mathrm{D} 1$} & \multirow[t]{2}{*}{$p$} \\
\hline & & $<8$ & $\geq 8$ & \\
\hline Patients $^{\mathrm{a}}$ & $(n=93)$ & $(n=10)$ & $(n=83)$ & \\
\hline $\begin{array}{l}\text { Length of stay in } \\
\text { intensive care unit } \\
\text { (d) }\end{array}$ & $16[2-123]$ & $16[2-123]$ & $16[2-96]$ & 0.80 \\
\hline Mortality D28 & $23(24.7)$ & $2(20)$ & $21(25.3)$ & 1 \\
\hline Infectious episodes & $(n=98)$ & $(n=11)$ & $(n=87)$ & \\
\hline Mortality D8 & $11(11.2)$ & $2(18.2)$ & $9(10.3)$ & 0.60 \\
\hline SOFA D8 & $3[0-12]$ & $2[0-6]$ & $3[0-12]$ & 0.75 \\
\hline
\end{tabular}

Data expressed in $n$ (\%) or median [min-max]

a Comparison according to the $C_{\max } / \mathrm{MIC}$ ratio observed during the first episode of infection treated with amikacin

In any event, it is even more striking to reach about $90 \%$ of PK/PD target attainment with these lower amikacin $C_{\text {max }}$, which seems related to low amikacin MICs.

Amikacin median MICs of all GNBs identified in our study was $2 \mathrm{mg} / \mathrm{L}$ [0.19-16] and the median MIC of Pseudomonas aeruginosa was $3 \mathrm{mg} / \mathrm{L}$ [1-8]. These results were comparable to amikacin MICs distribution for GNB published by EUCAST and in the literature [18, 19].

Unsurprisingly, in the group of infectious episodes that did not reach the $C_{\max } / \mathrm{CMI}$ ratio target, the median MIC of amikacin was higher (8 mg/L [4-16]). But excluding intermediate susceptibility $\mathrm{GNBs}$, a $C_{\max } / \mathrm{CMI}$ ratio $\geq 8$ was achieved in $91 \%$ of treated infections.

Few other studies reported inconsistencies between calculated $C_{\max }$ or $C_{\max } / \mathrm{MIC}$ (using clinical breakpoints) and measured $C_{\max } / \mathrm{MIC}$ (using measured MICs). A study based on measured MICs (for some patients enrolled), reported a $C_{\text {max }} / \mathrm{MIC}$ ratio $\geq 10$ in $93 \%$ of cases, with a median loading dose of $29.6 \mathrm{mg} / \mathrm{kg}$, while target amikacin $C_{\max }$ was only achieved in $77 \%$ of cases [20]. Similarly, Pajot et al. reported that $C_{\max } / \mathrm{MIC}$ ratio $\geq 10$ was achieved in $87 \%$ patients with documented ventilator-associated pneumonia treated with only $20 \mathrm{mg} / \mathrm{kg}$ amikacin [18]. Finally, De Winter et al. in an emergency department, in which a cohort of patients with septic shock/severe sepsis received $25 \mathrm{mg} / \mathrm{kg}$ amikacin, showed that $C_{\max } / \mathrm{MIC}$ ratio $\geq 8$ was achieved in $76 \%$ of cases when using critical MICs (EUCAST), and in 95\% of cases when using measured MICs [21]. 
These findings suggest that an exclusive focus on target $C_{\text {max }}$ without MIC measurement is probably not suitable to evaluate the pharmacodynamic efficacy of amikacin therapy in clinical studies. Thus, added value of daily practice amikacin pharmacodynamic assessment is also uncertain, as the probability of pharmacodynamic failure to treat susceptible GNBs with a $25 \mathrm{mg} / \mathrm{kg}$ amikacin dose is less than $10 \%$ when evaluated by the measured $C_{\max } /$ $\mathrm{MIC}$ ratio in several different studies.

Nevertheless, when the MIC is above $4 \mathrm{mg} / \mathrm{L}$, the risk of pharmacological failure is higher (around 40\%) and clinicians should keep in mind the key role of the MIC, particularly when Pseudomonas aeruginosa is involved. Thus, dose adjustment could be relevant, based on local epidemiology (MICs distribution and/or P. aeruginosa infections incidence).

Increasing AMK loading dose could, however, lead to withhold the subsequent doses, if needed. Indeed, we reported a $C_{\min } \geq 2.5 \mathrm{mg} / \mathrm{L}$-when measured on D2-in 49/82 (60\%) of treated infections and Roger et al. found similar results with a $30 \mathrm{mg} / \mathrm{kg}$ loading dose $\left(C_{\min } \geq 2.5 \mathrm{mg} / \mathrm{L}\right.$ in $49 \%$ of their patients) [20].

No correlation was found between $C_{\text {max }} / \mathrm{MIC}$ ratio and clinical outcome on D8 or D28 in our study. Moore et al. and Kashuba et al. demonstrated, 30 years ago, that the clinical benefit of aminoglycosides for the treatment of GNB infections was optimal if $C_{\max }$ reach 8 to tenfold the MIC $[3,22]$. But recent studies in ICU patients have failed to demonstrate a potential impact of aminoglycoside pharmacodynamics on clinical outcome $[7,8,20$, 23]. This negative result should be put into perspective with the various variables that may possibly explain mortality in intensive care. The combination with another antibiotic, most often a $\beta$-lactam, could also explain the lack of demonstration.

Even so, the median $C_{\max /}$ MIC ratio in our study greatly exceeded the threshold proposed by Moore et al. [3] (23.1 versus 8 ), but the proportion of pharmacodynamic failure according to the following criteria $\left(C_{\max } / \mathrm{MIC}<8\right)$ was low, around $10 \%$, which represents a small cohort for statistical comparisons.

Our study has several limitations. First, it is a retrospective study, based on a prospective database in 2 participating ICUs and in daily practice, BGN-documented infections are not systematically assessed with measured amikacin MIC. Factors that led to measure the MIC could introduce a selection bias, leading to measure the MIC only in the most difficult clinical situations. Nevertheless, the patients evaluated in our study are similar to those evaluated by De Montmollin et al. and Taccone et al. (in term of SAPS II score and mortality), allowing indirect comparison of our data with the literature $[7,8]$. Second, we did not assess the incidence of renal toxicity following amikacin administration. However, $64 \%$ of infections were treated with single daily dose of amikacin, minimizing the risk of nephrotoxicity. In addition, data from the literature do not report an increase in renal toxicity following the initial dose [24]. Gàlvez et al. also showed that a dose of $30 \mathrm{mg} / \mathrm{kg} /$ day amikacin was not associated with a higher incidence of nephrotoxicity than 15 or $25 \mathrm{mg} /$ $\mathrm{kg}$ /day regimen [6]. Finally, we studied the pharmacodynamic profile of amikacin during the first $24 \mathrm{~h}$ of administration. This is consistent with usual durations of aminoglycoside treatments (48 to $72 \mathrm{~h}$ ) and with data reported by Kashuba et al. [22] that highlighted the impact of the first aminoglycoside dose on patient's clinical outcome.

\section{Conclusion}

In critically ill patients treated with amikacin for susceptible Gram-negative bacilli infections, a $25 \mathrm{mg} / \mathrm{kg}$ (TBW) single daily dose actually achieved pharmacodynamic target in more than $90 \%$ of treated infections. Thus, in light of these results, the current trend of amikacin increase dose in the treatment of severe infections does not appear justified when local GNB ecology and amikacin MICs distribution are similar to ours. The relevance of systematic $C_{\max }$ measurement is also questionable or may require MIC measurement as well to ensure a reliable pharmacodynamic target assessment.

\section{Supplementary information}

Supplementary information accompanies this paper at https://doi. org/10.1186/s13613-020-00685-5.

Additional file 1: Table S1. Comparison of patients and treated infections based on the $C_{\max } / C M I$ ratio. Data presented in $\mathrm{n}(\%)$ or median [minmax]. Table S2. Comparison of patients and treated infections according to clinical outcome on D8 evaluated by SOFA score. Data presented in $n$ (\%) or median [min-max]. Table S3. Comparison of patients and infections treated according to mortality on D28. Data presented in $n(\%)$ or median [min-max]. Table S4. PK/PD parameters observed in intensive care unit (recent studies). Figure S1. MICs distribution of all bacteria identified and considered responsible for infections

\section{Abbreviations}

BMI: Body mass index; $C_{\text {max }}$ : Peak serum concentration; $C_{\text {min }}$ : Minimum concentration; EUCAST: European Committee on Antimicrobial Susceptibility Testing; GNB: Gram-negative bacilli; ICU: Intensive care unit; MIC: Minimal inhibitory concentration; PD: Pharmacodynamic; PK: Pharmacokinetic; SAPS 2: Simplified Acute Physiology Score; SOFA: Sequential Organ Failure Assessment; TBW: Total body weight.

Acknowledgements

The authors thank Prof Catherine Paugam and Prof Vincent Jullien for their close reading of the manuscript. 


\section{Authors' contributions}

EL and OP had full access to all of the data in the study and take responsibility for the integrity of the data and the accuracy of the data analysis. Concept and design: OP, EL, and ME. Acquisition, analysis, or interpretation of data: AC, NG, $M E, E L$, and ST. Drafting of the manuscript: EL, ME and OP. Critical revision of the manuscript for important intellectual content: OP, HM and PM. Statistical analysis: OP and MD. Supervision: OP. All authors read and approved the final manuscript.

\section{Funding}

Not applicable

\section{Availability of data and materials}

The datasets used and analyzed during the current study are available from the corresponding author on reasonable request.

\section{Ethics approval and consent to participate}

The ANSM (French National Agency for Medicines and Health Products Safety) registration number of the study is 2017-A01083-50. French Data Protection Agency declaration of the database was done. The local hospital ethics committee was consulted and did not indicate the need for a formal approval, according to French law [9].

\section{Consent for publication}

Not applicable.

\section{Competing interests}

Dr. MONTRAVERS reports personal fees and non-financial support from Astellas, AstraZeneca, Basilea, Bayer, Cubist, Menarini, MSD, Parexel, Pfizer, Tetraphase and The Medicines Company unrelated to the submitted work. Dr PAJOT reports personal fees from MSD unrelated to the submitted work. No other disclosures were reported.

\section{Author details}

${ }^{1} \mathrm{CH}$ Argenteuil, réanimation polyvalente, 69 rue du Lieutenant-Colonel Prudhon, Argenteuil, France. ${ }^{2} \mathrm{CHU}$ Bichat, réanimation chirurgicale, Paris, France. ${ }^{3}$ INSERM UMR1 188 Diabète - Athérothrombose - Thérapies Réunion Océan Indien (DéTROI), Saint-Denis de la Réunion, Université de la Réunion, Réunion, France. ${ }^{4} \mathrm{CHU}$ Bichat, maladies infectieuses et tropicales, Paris, France. ${ }^{5} \mathrm{CH}$ Argenteuil, microbiologie, Argenteuil, France. ${ }^{6} \mathrm{CHU}$ Bichat, microbiologie, Paris, France.

Received: 10 March 2020 Accepted: 20 May 2020

Published online: 08 June 2020

\section{References}

1. Kollef MH, Sherman G, Ward S, Fraser VJ. Inadequate antimicrobial treatment of infections: a risk factor for hospital mortality among critically ill patients. Chest. 1999;115:462-74.

2. Rhodes A, Evans LE, Alhazzani W, Levy MM, Antonelli M, Ferrer R, et al. Surviving sepsis campaign: international guidelines for management of sepsis and septic shock: 2016. Intensive Care Med. 2017;43:304-77. https ://doi.org/10.1007/s00134-017-4683-6.

3. Moore RD, Lietman PS, Smith CR. Clinical response to aminoglycoside therapy: importance of the ratio of peak concentration to minimal inhibitory concentration. J Infect Dis. 1987;155:93-9.

4. EUCAST. Aminoglycosides: http://www.eucast.org/fileadmin/src/media/ PDFs/EUCAST_files/Breakpoint_tables/v_10.0_Breakpoint_Tables.pdf.n.d.

5. ANSM. Bon usage des aminosides administrés par voie injectable: gentamicine, tobramycine, netilmicine, amikacine - Mise au point 2011.

6. Gálvez R, Luengo C, Cornejo R, Kosche J, Romero C, Tobar E, et al. Higher than recommended amikacin loading doses achieve pharmacokinetic targets without associated toxicity. Int J Antimicrob Agents. 2011;38:14651. https://doi.org/10.1016/j.ijantimicag.2011.03.022.

7. de Montmollin E, Bouadma L, Gault N, Mourvillier B, Mariotte E, Chemam $\mathrm{S}$, et al. Predictors of insufficient amikacin peak concentration in critically ill patients receiving a 25 ? $\mathrm{mg} / \mathrm{kg}$ total body weight regimen. Intensive Care Med. 2014;40:998-1005. https://doi.org/10.1007/s00134-014-3276-X.
8. Taccone F, Laterre P-F, Spapen H, Dugernier T, Delattre I, Layeux B, et al. Revisiting the loading dose of amikacin for patients with severe sepsis and septic shock. Crit Care. 2010;14:R53. https://doi.org/10.1186/cc8945.

9. Décret $n^{\circ}$ 2016-1537 du 16 novembre 2016 relatif aux recherches impliquant la personne humaine. Disponible sur https://www.legifrance.gouv. fr/eli/decret/2016/1/16/AFSP1621392D/jo/texte Alias: https://www.legif rance.gouv.fr/eli/decret/2016/11/16/2016-1537/jo/texte.n.d.

10. CDC. CDC/NHSN Surveillance Definitions for Specific Types of Infections. Available of https://www.cdc.gov/nhsn/pdfs/pscmanual/17pscnosin fdef_current.pdf.n.d.

11. Blaser J, König C, Fatio R, Follath F, Cometta A, Glauser M. Multicenter quality control study of amikacin assay for monitoring once-daily dosing regimens. Ther Drug Monit. 1995;17:133-6. https://doi.org/10.1097/00007 691-199504000-00005.

12. Le Gall JR, Lemeshow S, Saulnier F. A new simplified acute physiology score (SAPS II) based on a European/North American multicenter study. JAMA. 1993;270:2957-63.

13. Vincent JL, Moreno R, Takala J, Willatts S, De Mendonça A, Bruining $\mathrm{H}$, et al. The SOFA (Sepsis-related Organ Failure Assessment) score to describe organ dysfunction/failure On behalf of the Working Group on Sepsis-Related Problems of the European Society of Intensive Care Medicine. Intensive Care Med. 1996:22:707-10.

14. Boidin C, Jenck S, Bourguignon L, Torkmani S, Roussey-Jean A, Ledochowski S, et al. Determinants of amikacin first peak concentration in critically ill patients. Fundam Clin Pharmacol. 2018. https://doi.org/10.1111/ fcp. 12374.

15. Roberts JA, Abdul-Aziz MH, Lipman J, Mouton JW, Vinks AA, Felton TW, et al. Individualised antibiotic dosing for patients who are critically ill: challenges and potential solutions. Lancet Infect Dis. 2014;14:498-509. https://doi.org/10.1016/S1473-3099(14)70036-2.

16. Allou N, Bouteau A, Allyn J, Snauwaert A, Valance D, Jabot J, et al. Impact of a high loading dose of amikacin in patients with severe sepsis or septic shock. Ann Intensive Care. 2016. https://doi.org/10.1186/s1361 3-016-0211-z

17. Burdet C, Pajot O, Couffignal C, Armand-Lefèvre L, Foucrier A, Laouénan $C$, et al. Population pharmacokinetics of single-dose amikacin in critically ill patients with suspected ventilator-associated pneumonia. Eur J Clin Pharmacol. 2015;71:75-83. https://doi.org/10.1007/s00228-014-1766-y.

18. Pajot O, Burdet C, Couffignal C, Massias L, Armand-Lefevre L, Foucrier A, et al. Impact of imipenem and amikacin pharmacokinetic/pharmacodynamic parameters on microbiological outcome of Gram-negative bacilli ventilator-associated pneumonia. J Antimicrob Chemother. 2015;70:1487-94. https://doi.org/10.1093/jac/dku569.

19. EUCAST. Antimicrobial wild type distributions of microorganisms. https:// mic.eucast.org/Eucast2.n.d.

20. Roger C, Nucci B, Louart B, Friggeri A, Knani H, Evrard A, et al. Impact of $30 \mathrm{mg} / \mathrm{kg}$ amikacin and $8 \mathrm{mg} / \mathrm{kg}$ gentamicin on serum concentrations in critically ill patients with severe sepsis. J Antimicrob Chemother. 2016;71:208-12. https://doi.org/10.1093/jac/dkv291.

21. De Winter S, Wauters J, Meersseman W, Verhaegen J, Van Wijngaerden E, Peetermans W, et al. Higher versus standard amikacin single dose in emergency department patients with severe sepsis and septic shock: a randomised controlled trial. Int J Antimicrob Agents. 2018;51:562-70. https://doi.org/10.1016/j.ijantimicag.2017.11.009.

22. Kashuba AD, Nafziger AN, Drusano GL, Bertino JS. Optimizing aminoglycoside therapy for nosocomial pneumonia caused by gram-negative bacteria. Antimicrob Agents Chemother. 1999;43:623-9.

23. Duszynska W, Taccone F, Hurkacz M, Kowalska-Krochmal B, WielaHojeńska A, Kübler A. Therapeutic drug monitoring of amikacin in septic patients. Crit Care. 2013;17:R165. https://doi.org/10.1186/cc12844.

24. Mingeot-Leclercq MP, Tulkens PM. Aminoglycosides: nephrotoxicity. Antimicrob Agents Chemother. 1999;43:1003-12.

\section{Publisher's Note}

Springer Nature remains neutral with regard to jurisdictional claims in published maps and institutional affiliations. 